\title{
Inappropriate and Irrational Use of Medicines Prescribed to the Geriatric Patients in Pakistan
}

\author{
Amman Ullah, Gul Majid Khan*, Fakhar-ud-Din ${ }^{\#}$ \\ Department of Pharmacy, Faculty of Biological Sciences, Quaid-i-Azam University, Islamabad, \\ 45320 Pakistan
}

\begin{abstract}
*Corresponding Author: Gul Majid Khan, Professor \& Chairman, Department of Pharmacy, Quaid-iAzam University, Islamabad, Pakistan, Email: gmkhan@qau.edu.pk

${ }^{\#}$ Co-corresponding Author: Fakhar-ud-Din, Assistant professor, Department of Pharmacy, Quaid-iAzam University, Islamabad, Pakistan, Email: fudin@qau.edu.pk
\end{abstract}

\section{Abstract}

Objective: This study aims to evaluate the rational use of medicines among geriatric patients admitted to different hospitals.

Methodology: A retrospective study was conducted for the collection of data from geriatric patients (age $\geq$ 60 years) admitted in the government hospitals. A clinical data of the geriatric patients admitted in medical unit were reviewed. The data was analyzed using descriptive and inferential statistics. The rational use of the drug was evaluated by using the WHO and Beer's criteria.

Results: A total of 390 geriatric cases was selected from three government hospitals. The total number of medicines prescribed was 2682 and the average number of medicines per prescription was 6.88. The percentage of generic drugs was $47.2 \%$ (184). Percentage of parenteral and antibiotic were $93.8 \%$ (366) and $72.6 \%$ (283) respectively, while the percentage of drugs from the National Essential Drug List (NEDL) was 99.2\%. Polypharmacy was observed in 334 (85.6\%) prescriptions. Potentially inappropriate medicines according to Beer's criteria were $58.5 \%$. A significant association was present between inappropriate prescribing in geriatrics and different hospitals $(p<0.001)$, the number of drugs prescribed in geriatrics and different hospitals $(p<0.001)$ and the number of drugs and inappropriate prescribing $(p<0.001)$.

Conclusion: An increased number of prescription errors were present including polypharmacy, increased number of parenteral, antibiotics, and less number of drugs with generic names. It could be concluded that identification of the problem associated with prescription is the major step to remove the polypharmacy and inappropriate prescribing in geriatrics.

Keywords: Geriatrics, Beer's criteria, irrational prescribing, polypharmacy, inappropriate medicines.

\section{INTRODUCTION}

Gerontology derived from the Greek word geront meaning "old man". Geriatrics is a health discipline "encompassing psychosocial, economic, historical and physiological factors" for adults of 65 years and older [1]. Human population is increasing day-by-day. In early twentieth century only $1 \%$ of the human population was more than 65 years old, however, a significant increase was observed (up to 6\%) at the end of twentieth century and it is believed that it may increase up to $20 \%$ in 2050 [2]. Approximately 60\% of elders live in developing countries and it will rise to $70 \%$ in 2020 [3]. Pakistan is included in developing countries with a total population of 194 million in 2014 and it may rise up to 348 million in 2050. Average life expectancy in Pakistan is 65 years and $4 \%$ of the elder form total population. Owing to this increased geriatric population, challenges for health care providers are being increased [4].

Improvement in socioeconomic and health consequences increase the life expectancy and decrease the fertility rate $[5,6]$, leading to increased elder population. This unusual changes in geriatric population had increased the burden of chronic diseases and chances of disability [3]. In spite of socioeconomic instabilities in Pakistan, the population of geriatrics is increasing. Chances of chronic diseases, loss of muscle mass, disability and 
falls are more in Pakistan, because people lead asedentary lifestyle [7]. Commonly reported chronic diseases in elders are hypertension (42.5\%), diabetes mellitus (28.1\%) and arthritis (26.6\%) [8]. Chronic diseases are the major causes of death and disability worldwide. In Pakistan, $42 \%$ of deaths reported due to chronic diseases and death rate will increase by $27 \%$, but death due to diabetes increase by $51 \%$ which is second most commonly reported chronic disease [9].

One of the reasons elders have chronic and several concomitant diseases is their use of multiple medications fora longer period of time, leading to enhanced risks of morbidity and mortality [10]. More than $30 \%$ of geriatrics hospital admissions are due to that drug related problems [11]. Factors which cause the drugrelated problems in geriatrics are multiple diseases, inappropriate prescribing, polypharmacy, drug interactions and change in pharmacokinetics and pharmacodynamics [1113]. The most important cause of potentially harmful adverse drug reactions in geriatrics is the inappropriate use of drugs. The prevalence of inappropriate use of drugs ranges from 7.8 to $52 \%$ [9-11, 13-15]. Many potentially inappropriate drugs prescribed as a first line treatment by many health care providers which cause harmful drug interactions with less beneficial outcomes [16]. To avoid the use of inappropriate drugs in geriatrics Mark H. Beers developed the criteria in 1911 that was used in nursing home population [17]. Beers updated the criteria in 1997 including the 28 medicines or classes of medicines that were potentially inappropriate to use in geriatrics [18]. Recently in 2012, The American Geriatrics Society (AGS) and a panel of 11 experts updated the Beers criteria and named as updated 2012 AGS Beers Criteria. This criterionincludes 53 medications or classes of medications that were potentially inappropriate to use in geriatrics [16]. In Pakistan, 4\% of the total population is geriatrics [4] and not so much work done in above aspects in case of geriatrics. Therefore, the main aim of this study is to detect the polypharmacy in geriatrics and find out the inappropriate use of drugs in geriatrics in different areas of Pakistan.

\section{METHODS}

\subsection{Study Design and Setting}

A retrospective study design was adopted [14, 19] to estimate the rational and inappropriate use of medicines among geriatric patients in different government hospitals. This study was conducted in three government hospitals of Southern Punjab, Pakistan named as Bahawalpur Victoria Hospital (BVH) Bahawalpur, Nishter Hospital Multan and DHQ Bahawalnagar. The two hospitals were academic and one was non-academic. These are the only Government hospitals providing healthcare facilities to geriatrics patients in those areas. The ethical committee of Quaid-iAzam University had approved the design of this study.

\subsection{Participants and Data Collection}

All the cases of geriatric patients having age 60 years or more than 60 years $[13,19]$ reported in the medicine unit of the selected hospitals (as indoor patients) during the specified time period (June 2016 to March 2017) were included in the study. The total number of selected cases who meet the inclusion criteria were 390 . The criteria for the inclusion of patients were, having been treated in inpatient department and age 60 or more than 60 years. Patients using two or more than two medicines were included because study is focusing on polypharmacy. A data was collected from the hospitals by using the medical records of geriatric patients. A standardized information form was designed after comprehensive literature review to collect the data. Age, gender, prescription medicines and medical diagnosis were the parameters of interest.

\subsection{Data Analysis}

An updated 2012 Beers criteria was used to find the appropriateness of the prescribed drugs [20]. A WHO prescribing indicators were used to check the irrational use of medicines. WHO prescribing indicators were included number of drugs, parenteral and antibiotics prescribed. It also described the percentage of drugs prescribed from National essential drug list. Polypharmacy was identified from the number of prescribed drugs that are more than 5 per prescription. All the data regarding the patient's demographic and medication use was entered and analyzed by using Statistical Package for the Social Sciences (version 21.0) and Stata. Descriptive statistical methods were used to summarize the data. Chi-square and linear regression were used to find out the association between inappropriate prescribing in geriatrics and different hospitals, inappropriate prescribing 
in geriatrics and gender, the number of drugs prescribed in geriatrics and different hospitals, the number of drugs and inappropriate prescribing. For all of these analyses, statistical significance was defined by $\mathrm{P}<.05$.

\section{RESULTS}

\subsection{Demographic Characteristics}

Out of the 390 cases of geriatrics, 234 (60\%) were males and $156(40 \%)$ were females (Table I). Age of the geriatric patients in all of the hospitals were from 60 to 110 years. The mean age of the patients was $67.5 \pm 8.657$. Among these 390 geriatric patients, 163 (41.8\%) patients were in the range of 60-64 years, 78 (20\%) were in the range of 65-69 years, 68 $(17.4 \%)$ were in the range of $70-74$ years, 24 $(6.2 \%)$ were in the range of 75-79 years and 57 $(14.6 \%)$ were of 80 years and more than 80 years of age (Table I).

TableI. Demographic characteristics and diagnosed diseases of the geriatric patients

\begin{tabular}{|l|l|l|}
\hline \multicolumn{1}{|c|}{ Variables } & Frequency & $\begin{array}{c}\text { Percentage } \\
(\mathbf{\%})\end{array}$ \\
\hline Age (Mean \pm SD $^{*}$ ) & $\mathbf{( 6 7 . 5 \pm 8 . 6 5 7 )}$ & \\
$60-64$ & 163 & 41.8 \\
$65-69$ & 78 & 20.0 \\
$70-74$ & 68 & 17.4 \\
$75-79$ & 24 & 06.2 \\
$80 \&>80$ & 57 & 14.6 \\
\hline Gender & 234 & 60 \\
Male & 156 & 40 \\
Female & & \\
Mostly Diagnose & 114 & 26.9 \\
Diseases & 75 & 17.7 \\
Cardiovascular & 71 & 16.8 \\
diseases & 53 & 12.5 \\
Respiratory diseases & 50 & 11.8 \\
Cerebrovascular & 50 & 11.8 \\
diseases & 50 & 1.4 \\
Endocrine disorders & 6 & 1.1 \\
Gastrointestinal & 5 & \\
disorders & & \\
Infectious diseases & & \\
Renal diseases & & \\
Liver diseases & & \\
*SD: Standard deviation &
\end{tabular}

\subsection{Diagnosed Diseases}

The most common diseases diagnosed in geriatrics are presented in Table I. The frequently diagnosed disease were cardiovascular 114 (26.9\%), followed by respiratory diseases $75(17.7 \%)$, cerebrovascular diseases $71(16.8 \%)$, endocrine disorders 53 $(12.5 \%)$, gastrointestinal disorders and infectious diseases 50 (11.8\%) (Figure 1). Less commonly diagnosed diseases were renal diseases $6(1.4 \%)$ and liver diseases 5(1.1\%).

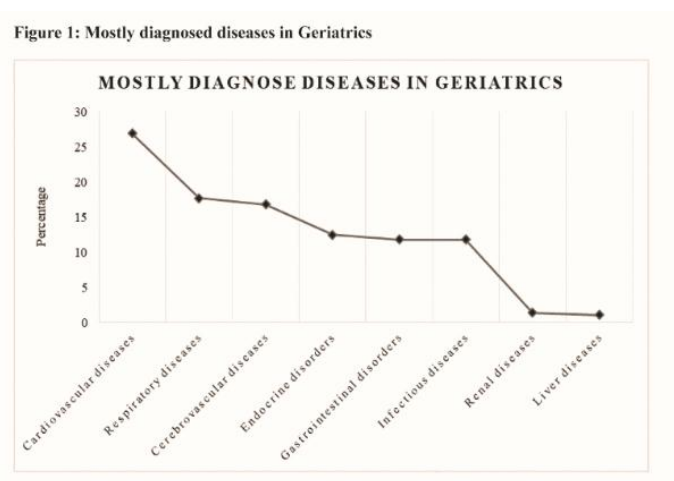

3.3. Polypharmacy in Geriatrics

TableII. Polypharmacy in geriatrics

\begin{tabular}{|c|c|c|}
\hline $\begin{array}{c}\text { Number of } \\
\text { medicines }\end{array}$ & Frequency & $\begin{array}{c}\text { Percentage } \\
(\boldsymbol{\%})\end{array}$ \\
\hline$<5$ & 56 & 14.4 \\
\hline $5-10$ & 296 & 75.9 \\
\hline$>10$ & 38 & 9.7 \\
\hline
\end{tabular}

TableIII. Correlation between different variables

\begin{tabular}{|c|c|c|c|c|}
\hline & \multicolumn{3}{|c|}{$\begin{array}{l}\text { Inappropriate } \\
\text { prescribing }\end{array}$} & $\begin{array}{l}\text { p- } \\
\text { value }\end{array}$ \\
\hline & \multicolumn{2}{|c|}{ Yes $(\%)$} & No $(\%)$ & \\
\hline \multirow{10}{*}{$\begin{array}{l}\text { Hospitals } \\
\text { DHQ } \\
\text { Bahawalnagar } \\
\text { Bahawalpur } \\
\text { Victoria } \\
\text { Nishtar } \\
\text { Hospital } \\
\text { Multan } \\
\end{array}$} & \multirow{8}{*}{\multicolumn{2}{|c|}{$\begin{array}{l}93(71.5) \\
89(68.5) \\
46(35.4)\end{array}$}} & \multirow{8}{*}{$\begin{array}{l}37(28.5) \\
41(31.5) \\
84(64.6)\end{array}$} & \\
\hline & & & & $<0.001$ \\
\hline & & & & \\
\hline & & & & \\
\hline & & & & \\
\hline & & & & \\
\hline & & & & \\
\hline & & & & \\
\hline & \multicolumn{3}{|c|}{ Number of medicines } & \\
\hline & $\begin{array}{l}<5 \\
(\%)\end{array}$ & $\begin{array}{l}5-10 \\
(\%)\end{array}$ & $\begin{array}{l}>10 \\
(\%)\end{array}$ & \\
\hline \multirow{9}{*}{$\begin{array}{l}\text { Hospitals } \\
\text { DHQ } \\
\text { Bahawalnagar } \\
\text { Bahawalpur } \\
\text { Victoria } \\
\text { Nishtar } \\
\text { Hospital } \\
\text { Multan } \\
\end{array}$} & & & & \\
\hline & & & & \\
\hline & $(0.8)$ & $(75.4)$ & $(23.8)$ & $<0.001$ \\
\hline & 24 & 100 & & \\
\hline & $(18.5)$ & $(76.9)$ & $(4.6)$ & \\
\hline & & & & \\
\hline & $(23.8)$ & $(75.4)$ & $(0.8)$ & \\
\hline & \multicolumn{3}{|c|}{ Number of medicines } & \\
\hline & $\begin{array}{l}<5 \\
(\%) \\
\end{array}$ & $\begin{array}{l}5-10 \\
(\%)\end{array}$ & $\begin{array}{l}>10 \\
(\%)\end{array}$ & \\
\hline \multirow{3}{*}{$\begin{array}{l}\text { Inappropriate } \\
\text { Prescribing } \\
\text { Yes } \\
\text { No }\end{array}$} & 16 & \multirow{3}{*}{$\begin{array}{l}181 \\
(78.4) \\
115 \\
(72.3)\end{array}$} & 24 & $<0.001$ \\
\hline & $(7.0)$ & & $(10.5)$ & \\
\hline & $\begin{array}{l}40 \\
(24.7)\end{array}$ & & $\begin{array}{l}14 \\
(8.6)\end{array}$ & \\
\hline
\end{tabular}

Among the total prescriptions studied (390), 56 (14.4\%) prescriptions had less than 5 drugs, 296 (75.9\%) prescriptions had 5-10 drugs and 38 (9.7\%) prescriptions had more than 10 
prescriptions. The polypharmacy was found in $334(85.6 \%)$ prescriptions (Table II). There was a significant correlation present between the number of prescribed medicines and different hospitals. The polypharmacy was practiced mostly in DHQ Bahawalnagar 129 (99.2\%), followed by BVH Bahawalpur 106 (81.5\%) and less commonly practiced in Nishtar Hospital Multan 99 (76.2\%) (Table III).

\subsection{WHO Prescribing Indicators}

Five prescribing indicators selected by WHO are shown in Table IV. The average number of drugs prescribed were $6.88 \pm 2.56$ having the range of 1-16, the maximum number of drugs prescribed were 16, but according to WHO standard the average number of drugs prescribed should be 1.6-1.8. Only $47.2 \%$ (184) of drugs were prescribed by generic while according to WHO criteria all the drugs must be prescribed by generic (Figure 2). An average number of prescribed drugs with generic were $0.8 \pm 1.017$ and the maximum number of drugs prescribed by generic per prescription was 4 .

TableIV. Inappropriate prescribing (WHO criteria) in geriatrics

\begin{tabular}{|l|l|l|l|}
\hline \multicolumn{1}{|c|}{$\begin{array}{c}\text { Prescribing } \\
\text { Indicators }\end{array}$} & $\begin{array}{c}\text { Obtained } \\
\text { Value }\end{array}$ & $\begin{array}{c}\text { WHO } \\
\text { Standard }\end{array}$ & $\begin{array}{c}\text { Rang } \\
\text { e }\end{array}$ \\
\hline $\begin{array}{l}\text { Average } \\
\text { number of } \\
\text { drugs per } \\
\text { prescription }\end{array}$ & 6.88 & $1.6-1.8$ & $1-16$ \\
\hline $\begin{array}{l}\text { Percentage of } \\
\text { drugs } \\
\text { prescribed with } \\
\text { generic }\end{array}$ & $47.2 \%$ & $100 \%$ & $0-4$ \\
\hline $\begin{array}{l}\text { Percentage of } \\
\text { parenteral } \\
\text { prescribed }\end{array}$ & $93.8 \%$ & $13.4-$ & $0-9$ \\
\hline $\begin{array}{l}\text { Percentage of } \\
\text { antibiotic } \\
\text { prescribed }\end{array}$ & $72.6 \%$ & $24.1 \%$ & $0-26.8 \%$ \\
\hline $\begin{array}{l}\text { Percentage of } \\
\text { drugs from } \\
\text { NEDL* }\end{array}$ & $99.2 \%$ & $100 \%$ & $0-8$ \\
\hline
\end{tabular}

*NEDL: National Essential Drug List

The percentage of prescriptions having at least one parenteral prescribed were $93.8 \%$ (366) but according to WHO standard the percentage of parenteral must be in the range of 13.4-24.1\% (Figure 2). The average number of parenteral were $3.09 \pm 1.712$ and the maximum number of parenteral prescribed with generic per prescription were 9. Percentage of prescription having at least one antibiotic prescribed to geriatrics were $72.6 \%$ (283) but according to WHO criteria percentage of antibiotic prescribed should be 20-26.8\% (Figure 2). The average number of antibiotic prescribed were $1.05 \pm 0.872$ and the maximum number of antibiotic prescribed by generic per prescription were 5. Most of the prescribed drugs were from the National Essential Drug List (NEDL) that were 387 (99.2\%) (Figure 2). The average number of prescribed drugs from NEDL were $3.75 \pm 1.8505$ and the maximum number of drugs prescribed prescription were 8 .

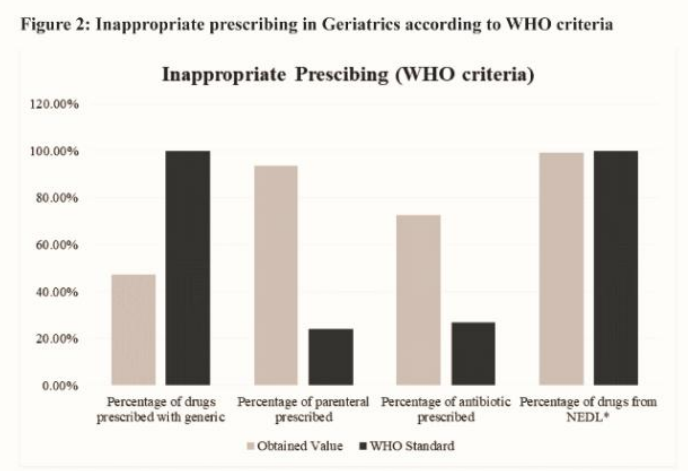

\subsection{Potentially Inappropriate Medicines}

TableV. Inappropriate prescribing (Beer's criteria) in geriatrics

\begin{tabular}{|l|l|l|l|}
\hline \multicolumn{2}{|c|}{ Variables } & Frequency & $\begin{array}{c}\text { Percentag } \\
\text { es (\%) }\end{array}$ \\
\hline $\begin{array}{l}\text { Inappropriate } \\
\text { prescribing }\end{array}$ & Yes & 228 & 58.5 \\
& No & 162 & 41.5 \\
\cline { 2 - 4 } & Total & $\mathbf{3 9 0}$ & $\mathbf{1 0 0 . 0}$ \\
\hline Number of & 0 & 162 & 41.5 \\
inappropriate & 1 & 162 & 41.5 \\
prescribing & 2 & 49 & 12.6 \\
& 3 & 15 & 3.8 \\
& 4 & 2 & 0.5 \\
\cline { 2 - 4 } & Total & $\mathbf{3 9 0}$ & $\mathbf{1 0 0 . 0}$ \\
\hline
\end{tabular}

A number of inappropriate prescribed drugs according to Beer's criteria is presented in Table V. Of the 390 prescriptions, 228 (58.5\%) prescriptions had at least one inappropriately prescribed drugs from Beer's generated inappropriately prescribed list of the drugs for geriatrics. The average number of inappropriately prescribed drugs were $0.8 \pm 0.839$ and the maximum number of inappropriately prescribed drugs per prescription were 4. A strong and positive correlation was found between the inappropriate prescribing and different hospitals $(\mathrm{p}=<0.001)$. Inappropriate prescribing was practiced mostly in DHQ Bahawalnagar (non-academic) 93 (71.5\%) out of 130, followed by Bahawalpur Victoria Hospital (academic) 89 (68.5\%) out of 130 and less commonly in Nishtar Hospital Multan (academic) that was $46(35.4 \%)$ out of 130 
(Table III). Chances of inappropriate prescribing increased as the number of prescribed medicines increased $(\mathrm{p}=<0.001)$. There was $181(78.4 \%)$ inappropriate prescribing out of 228 present when the number of drugs prescribed was 5-10 per prescription (Table III).

\section{DISCUSSION}

As compared to adults, the issue of polypharmacy is of particular concern in geriatrics. The polypharmacy is common is geriatric patients due to the presence of multiple diseases. Polypharmacy is defined as the use of five or more medicines per prescription. According to our study, the usage of five or more drugs was present in $85.6 \%$ prescriptions. This result correlates with the finding of Sapkota et al. [21], who find that the prevalence of polypharmacy in geriatrics was $76 \%$. This finding is also matched closely with the finding of Joshi et al. [22] according to which the prevalence of polypharmacy in geriatrics was $73 \%$. The study showed that the polypharmacy is significantly associated with inappropriate prescribing and with different hospitals. Polypharmacy in geriatrics associated with thesevere type of adverse reactions, drug interactions and also the cost of treatment which may lead towards non-adherence and noncompliance as the patients have more than 5 medicines to cope with. It is although not possible to remove the polypharmacy but patient feedback and pharmacist review of medications help to improve the practice and to encourage the prescriber to remove certain medicines to reduce Polypharmacy.

Our results exhibited a little practice of rational drug prescribing in health care setting. Rational drug prescribing can be defined as, "the use of the least number of drugs to obtain the best possible effect in the shortest period of time at a reasonable cost" [23]. The study showed that most of the prescriptions are inappropriate according to the WHO proposed criteria. According to WHO standard, the average number of drugs prescribed per prescription must be 1.6-1.8 but in this study, the average number of drug prescribed was 6.88 which is closely related to the finding of Taskeen et al. who find out that the average number of drugs prescribed in geriatrics was 6.07 [15]. According to WHO criteria, all the drugs must be prescribed with generic but $47.2 \%$ of drugs prescribed by generic was reported in this study, this finding confirmed studies conducted by Uchenna IH Eze and Adebiyi O Olowu [13] which was $48.9 \%$ and $53.6 \%$ by Joshi et al. [22]. Our result exhibited that the prescribers were not following the WHO prescriber indicator recommendations. Prescribing by generic name are cost effective because it allows the dispensing of various brands of the drug having the same chemical formula and efficacy that are cheaper. This is the basis of use of essential drug list [24].

According to our results, theuse of parenteral in geriatrics was too high, that is $93.8 \%$, both according to the WHO criteria which is 13.4$24.1 \%$ and according to the previous conducted studies like $30 \%$ find out by Sapkota et al. [21] and $7.05 \%$ find out by Taskeen et al. [15] In geriatrics the high rate of parenteral use could be due to swallowing problems and patient's compliance. The pressure from the geriatric patients and family members to prescribe parenteral for immediate relief may have contributed immensely to this high rate.

Percentage of the antibiotic prescribed according to our study was also very high, that is $72.6 \%$, but according to $\mathrm{WHO}$ standard it must be in the range of $20-26.8 \%$. This finding is also too high as compared to the reports of Sapkota et al. [21] that is $18 \%$. The reason for high rate of antibiotic use may be due to a number of infectious diseases, poor immunity and inappropriate facilities to check the infection causing agents.

Inappropriate prescribing is the main issue in case of the geriatric patients. It increases the burden of cost on the patients due to two main reasons including the ineffectiveness and adverse reactions of the drugs which may lead to hospitalization. Beer's proposed the criteria to find out the inappropriate drugs that should be avoided in geriatrics. Eze and Olowu, and Chitra et al. found out that more than half of the medicines prescribed to geriatrics were inappropriate according to the Beer's criteria, $[13,19]$ this finding is correlated with our finding because in our study we find $58.5 \%$ inappropriate prescribing. Many previous studies also find out that most of the medicines prescribed to the geriatrics were inappropriate, though the level of occurrence was less as compare to our study $[25,26]$.

Besides all these findings, this study evaluates the correlations between inappropriate prescribing in geriatrics and different hospitals, 
inappropriate prescribing in geriatrics and gender, the number of drugs prescribed in geriatrics and different hospitals, the number of drugs and inappropriate prescribing. Inappropriate prescribing was more common in non-academic healthcare settings as compared to academic healthcare settings. In all these variables, we find a significant correlation ( $p$ $<0.001)$ except between inappropriate prescribing in geriatrics and gender. There is no study conducted to find out this type of correlations. The only study conducted in this regard is to find out the correlation between a number of prescribed drugs and drug-drug interactions. The study conducted by Nobili et al., [28] Teixeira et al. [29] and Janchawee et al. [27] showed that there is a significant relationship between a number of prescribed drugs and drug-drug interactions.

\section{CONCLUSION}

Polypharmacy in geriatrics is common among all the hospitals of southern Punjab but more common among the hospitals in lower areas. The Same type of findings present in the case of inappropriate prescribing and rational use of drugs. More than $50 \%$ of the drugs prescribed to the geriatric patients were inappropriate according to Beer's criteria and inappropriate use of medicines were common in nonacademic hospitals. An increase number of prescription errors were also found in this study like polypharmacy, extensive use of parenteral, antibiotics and drugs with brand name. These errors highlight the need of paying attention towards prescriptions and prescribers to reduce the inappropriate prescribing, especially in geriatrics to avoid serious health related consequences. Special healthcare department should be established for geriatrics in hospitals to provide better healthcare facilities to geriatrics. The absence of pharmacist in healthcare sector leads to the inappropriate use of drugs. Both pharmacist and prescriber must be involved in prescribing and reviewing procedure to remove such type of errors, to improve the quality of life and to decrease the economic burden.

\section{LIMITATION}

There were some limitations in this study. First, the study used a convenient method to collect the data. Second, the study was conducted in a limited number of healthcare sectors. Three, only hospitalized patients were included in this study. Despite these limitations, the study provides important and necessary information about inappropriate prescribing and irrational use of medicines in geriatrics.

\section{ACKNOWLEDGMENT}

\section{AUTHOR'S CONTRIBUTION}

Study concept and design: Fakhar-ud-Din, Gul Majid Khan. Acquisition and interpretation of data: Ammanullah, Gul Majid Khan. Critical revision of manuscript: Ammanullah, Fakharud-Din, Gul Majid Khan. Study supervision: Gul Majid Khan, Fakhar-ud-Din.

\section{REFERENCES}

[1] Amella EJ. Geriatrics and Palliative Care: Collaboration for Quality of Life Until Death. Am J Hosp Palliat Care 2003;5:40-8.

[2] Strausbaugh LJ. Emerging Health CareAssociated Infections in the Geriatric Population. Emerg Infect Dis 2001;7:268-71.

[3] Ageing - Exploding the Myths. Geneva: Ageing and Health Programme (online). Available at: http://whqlibdoc.who.int/hq/ 1999/WHO_HSC_AHE_99.1.pdf. Accessed December 4, 2016.

[4] The 2014 World Health Data Sheet (online). Available at: http://www.prb.org/pdf14/2014world-population-data-sheet_eng.pdf. Accessed December 4, 2016.

[5] Mahmood N. Population and Development: Demographic Research at PIDE. Pakistan Institute of Development Economics, Islamabad, 2009.

[6] Gavrilov LA, Heuveline P. Aging of Population. In: Demeny P, McNicoll G, editors. The Encyclopedia of Population. New York: Macmillan Reference USA2003. p. 32-7.

[7] Aging in Pakistan-A New Challenge (online). Springer Science+Business Media, LLC 2010.

[8] Zafar SN, Ganatra HA, Tehseen S et al. Health and needs assessment of geriatric patients: results of a survey at a teaching hospital in Karachi. J PakMed Assoc 2006;56:470-4.

[9] Facing the Facts: The Impact of Chronic Disease in Pakistan (online). Available at: http://www.who.int/chp/chronic_disease_report /media/PAKISTAN.pdf. Accessed September 21, 2016.

[10] Merle L, Laroche M-L, Dantoine $\mathrm{T}$ et al. Predicting and preventing adverse drug reactions in the very old. Drugs \&Aging 2005;22:375-92.

[11] Schmader KE, Hanlon JT, Pieper CF et al. Effects of geriatric evaluation and management on adverse drug reactions and suboptimal 
prescribing in the frail elderly. Am $\mathrm{J}$ Med 2004;116:394-401.

[12] Gurwitz JH, Field TS, Harrold LR et al. Incidence and Preventability of Adverse Drug Events Among Older Persons in the Ambulatory Setting. JAMA 2003;289:1107-16.

[13] Eze UI, Olowu AO. Prescribing Patterns and Inappropriate Use of Medications in Elderly Outpatients in a Tertiary Hospital in Nigeria. Trop J Pharm Res 2011;10:19-25.

[14] Dennehy CE, Kishi DT, Louie C. Drug-related illness in emergency department patients. Am J Health Syst Pharm 1996;53:1422-6.

[15] Taskeen M, N A, Ali SR, Bharath R et al. A Study On Rational Drug Prescribing Pattern In Geriatric Patients In Hyderabad Metropolitan. J drug deliv ther 2012;2:109-113.

[16] The American Geriatrics Society 2012 Beers Criteria Update Expert Panel. American Geriatrics Society Updated Beers Criteria for Potentially Inappropriate Medication Use in Older Adults. J Am Geriatr Soc 2012;60:61631.

[17] Beers MH, Ouslander JG, Rollingher I et al. Explicit criteria for determining inappropriate medication use in nursing home residents. Arch Intern Med 1991;151:1825-32.

[18] Beers MH. Explicit criteria for determining potentially inappropriate medication use by the elderly. An update. Arch Intern Med 1997;157:1531-6.

[19] Chitra B, Sriram S, AnandavalliSukumaran Nair Manjuladevi BR et al. Rational Use of Drugs in Elderly at a Private Corporate Hospital. UJP 2013;2:102-5.

[20] The American Geriatrics Society 2012 Beers Criteria Update Expert Panel. American Geriatrics Society updated Beers Criteria for potentially inappropriate medication use in older adults. J Am Geriatr Soc 2012.

[21] Sapkota S, Pudasaini N, Singh C et al. Drug Prescribing Pattern And Prescription Error In
Elderly: A Retrospective Study Of Inpatient Record. Asian J Pharm Clin Res 2011;4:12932.

[22] Joshi MP, Sugimoto T, Santoso B. Geriatric Prescribing in the Medical Wards of a Teaching Hospital in Nepal. Pharmacoepidemiol Drug Saf 1997;6:417-21.

[23] Shankar PR, Upadhyay DK, Subish P. Drug utilisation among older inpatients in a teaching hospital in Western Nepal. Singapore Med J 2010;51:28.

[24] Adibe MO, Aguwa CN, Ukwe CV et al. Outpatient utilization of antidiabetic drugs in the south eastern Nigeria. Int $\mathrm{j}$ drug dev 2009;1:27-36.

[25] Zhan C, Sangl J, Bierman A et al. Potentially inappropriate medication use in the communitydwelling elderly: Findings from the 1996 Medical Expenditure Panel Survey. JAMA 2001;286:2823-9.

[26] Raji MA, Ostir GV, Markides KS et al. Potentially inappropriate medication use by elderly Mexican Americans. Ann Pharmacother 2003;37:1197-202.

[27] Janchawee B, Owatraporn T, Wongpoowarak $\mathrm{W}$ et al. Clinical drug interactions in outpatients of a university hospital in Thailand. J Clin Pharm Ther 2005;30:583-90.

[28] Nobili A, Pasina L, Tettamanti $M$ et al. Potentially severe drug interactions in elderly outpatients: results of an observational study of an administrative prescription database. J Clin Pharm Ther 2009;34:377-86.

[29] Doubova SV, Reyes-Morales H, Torres-Arreola LdP et al. Potential drug-drug and drug-disease interactions in prescriptions for ambulatory patients over 50 years of age in family medicine clinics in Mexico City. BMC Health Serv Res 2007; 7:147.

Citation: Amman Ullah, Gul Majid Khan \& Fakhar-ud-Din, Inappropriate and Irrational Use of Medicines Prescribed to the Geriatric Patients in Pakistan.ARC Journal of Public Health and Community Medicine.2018; 3(2):12-18. DOI: dx.doi.org/ 10.20431/2456-0596.0302003.

Copyright: (C) 2018 Authors. This is an open-access article distributed under the terms of the Creative Commons Attribution License, which permits unrestricted use, distribution, and reproduction in any medium, provided the original author and source are credited. 